\title{
Evaluating the cost effectiveness of using various types of stabilized base layers in flexible pavements
}

\author{
A. Francois, D. Offenbacker \& Y. Mehta \\ Center for Research and Education in Advanced Transportation Engineering Systems, Department of Civil \\ Engineering, Rowan University, Glassboro, New Jersey, USA
}

\begin{abstract}
This study was initiated with the aim of determining the cost effectiveness of utilizing various types of stabilizers in the base layer of flexible pavements. Five field sections that were formerly part of a controlled study conducted by Rhode Island Department of Transportation (RIDOT) were evaluated in this study. All field sections contained a 4.5 in. hot mix asphalt (HMA) surface layer and 1 in. granular subbase. Four of the five sections were constructed using stabilized base layers (i.e., calcium chloride $\left(\mathrm{CaCl}_{2}\right)$, Portland cement, geogrid, and bituminous (asphalt emulsion) stabilized base layers). A control section was constructed using 100\% untreated, recycled asphalt pavement (RAP) base layer. All sections were located on Rhode Island Route 165 (between utility poles 304 and 521). Falling weight deflectometer (FWD) tests were conducted on the field sections and the collected deflection data was used to back-calculate the elastic moduli for all layers on each highway segment. AASHTOWare Pavement ME Design simulations were conducted to determine the predicted fatigue and rutting performance of the flexible pavement sections. The results of the Pavement ME design simulations were used in conjunction with the RIDOT Pavement Structural Health Index (PSHI) to determine the total life cycle cost of each pavement section. Based on the results of the study it was determined that stabilization of base layers during full depth reclamation were not cost effective because pavement sections that contained stabilized bases had a higher total life cycle cost than the pavement section that contained an untreated base.
\end{abstract}

Keywords: Back-calculation, full depth reclamation, falling weight deflectometer testing, life cycle cost analysis

\section{INTRODUCTION}

The stiffness of the base layer in flexible pavement can significantly influence the tensile strains in the hot mix asphalt (HMA) layers and the compressive strains on the subgrade layer of the pavement system. Since the stiffness of the base layer depends on the material properties of that layer, the type of base layer used in a flexible pavement has a direct impact on the overall performance of flexible pavements. Two types of base layers are typically utilized in the flexible pavements: unbound aggregate bases and bound (stabilized) aggregate bases. Unbound aggregate bases consist of unmodified granular aggregates while stabilized bases consist of granular material bounded by a stabilizing agent. The main function of all base layers, regardless their type, is to provide support for the HMA layer(s) and to efficiently distribute traffic loads onto subgrade and/or subbase pavement layers.

The treatment of untreated granular aggregates with stabilizing agents provides bound bases with improved stability because stabilization increases aggregate interlock and facilitates

DOI: $10.1201 / 9781003222880-15$ 
load transfer. However, the actual stabilizing agents themselves contribute very little to the structural capacity of the bound base. There is a variety of stabilizing agents currently used to treat the base layers of flexible pavements. Some of the commonly used stabilizers in bound bases include: foamed asphalt, cutback asphalt, Portland cement concrete (PCC), geogrids, and calcium chloride $\left(\mathrm{CaCl}_{2}\right)$. The increased aggregate interlock provided by these stabilization agents enables load transfer in bound bases to be more efficient than the load transfer in unbound bases. There is a general consensus among researchers that the use of stabilizing agents in the base layer of flexible pavements improves the overall performance of that layer (Hungener et al. 2015, Wang et al. 2011, Abu-Farsakh et al. 2011, Tao et al. 2015, Tang et al. 2008 , and Ogundipe, 2014). However, there is limited insight on how different types of stabilized base layers compare in terms of their impact on the overall performance of flexible pavements and their overall cost effectiveness.

\section{GOAL}

Therefore, the goal of this study is to evaluate the performance and cost-effectiveness of using stabilized bases in HMA pavement systems. For this purpose, a life cycle cost analysis was conducted on five field sections each having a respective base materialunbound recycled asphalt pavement (RAP) base, calcium chloride stabilized base, bituminous stabilized base, Portland cement stabilized base, and geogrid stabilized base. Falling weight deflectometer (FWD) testing was conducted to determine the layer moduli of the pavement sections and Pavement ME design simulations were performed to evaluate the predicted performance of the sections. The results of the Pavement ME Design simulations were subsequently utilized to assess the relative condition of the pavement sections.

\section{FIELD SECTION DESCRIPTION}

Five field sections located on Route 165 (between utility poles 304 and 521) in Rhode Island (RI) were evaluated in this study. The sections were part of a controlled study by Rhode Island Department of Transportation (RIDOT) which, evaluated the long-term field performance of these sections. Four of the five sections were constructed using stabilized base layers and one was constructed as a control section using an unmodified, RAP aggregates base. Four different stabilizing agents (i.e., calcium chloride, Portland cement, geogrids, and emulsified asphalt) were utilized to construct the four stabilized base layers.

Figure 1 presents the pavement structure utilized in all five sections analyzed in this study. All sections contained a $114.3 \mathrm{~mm}$ HMA layer that consisted of a $50.8 \mathrm{~mm}$ surface course and $63.5 \mathrm{~mm}$ intermediate course. The sections also contained a $203.2 \mathrm{~mm}$, thick base layer, and $203.2 \mathrm{~mm}$ crushed gravel subbase layer. Additionally, the gradation of the base layers of all the pavement sections were similar. That is, 95 to $100 \%$ passing the No. 3 sieve $(6.7 \mathrm{~mm})$ and $2 \%$ to $15 \%$ passing the No. 200 sieve $(75 \mu \mathrm{m})$. During construction, all field sections underwent full depth reclamation (FDR). The section which contained the $\mathrm{CaCl}_{2}$ treated base, was stabilized using a $\mathrm{CaCl}_{2}$ solution (35\% alkali chloride, $2 \%$ sodium chloride, and $0.1 \%$ magnesium chloride). The PCC, stabilized base was constructed by uniformly blending $17.4 \mathrm{~kg} / \mathrm{m}^{2}$ of dry cement with pulverized RAP material. The geogrid stabilized base was mechanically reinforced at the interface of the base and subbase using polypropylene geogrids with triangular apertures. The bituminous stabilized base was treated with $3.62 \mathrm{~L} / \mathrm{m}^{2}$ of an anionic medium to rapid setting (HFMS-2) asphalt emulsion. 


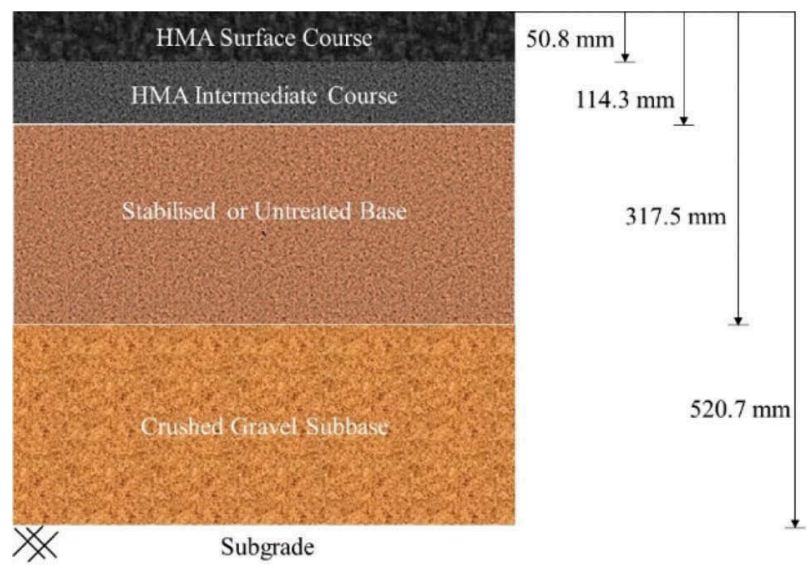

Figure 1. Pavement cross-section of five field sections.

\section{TESTING AND EVALUATION PLAN}

The testing plan adopted in this study to assess the cost effectiveness of the stabilized bases evaluated in this study involved: FWD testing, Pavement ME Design simulations and pavement condition assessment. FWD tests were conducted on all five field sections approximately one year after they were originally constructed. At each test location on the sections, four drop heights that corresponded to target loads of $29.4 \mathrm{kN}, 41.2 \mathrm{kN}, 58.8 \mathrm{kN}$, and $78.4 \mathrm{kN}$, respectively were utilized. Geophones were spaced at $0,200 \mathrm{~mm}, 300 \mathrm{~mm}, 450 \mathrm{~mm}, 600 \mathrm{~mm}$, $900 \mathrm{~mm}$, and $1200 \mathrm{~mm}$, respectively from the applied load. The collected pavement deflection data was then utilized to back-calculate the elastic moduli for all layers in all pavement sections. The back-calculation process was performed using the BAKFAA software which is a computer program developed and used by the Federal Aviation Administration (FAA). In this computer program, initial "seed" values for the moduli of respective pavement layers are used as inputs in BAKFAA. Deflections are then calculated by a subroutine program which runs a static-linear elastic analysis using concepts from the multilayered elastic theory. During this process, the original seed layer moduli values are altered using an iterative method in which the root mean squared error between computed and measured deflections is minimized by matching the radius of curvature of the measured and calculated deflection basins.

The Pavement ME Design simulations entailed the use of level 3 inputs. Table 1 presents a summary of all inputs utilized in conducting the Pavement ME Design simulations. Data collected from weigh in motion (WIM) stations that were in close proximity to Route 165 was used to determine a vehicle class distribution that was representative of traffic on Route 165. The back-calculated layer moduli were utilized as inputs in the Pavement ME Design simulations along with the layer thicknesses presented in Figure 1. Climate data obtained from a weather station located in Providence, RI were also used as inputs in the Pavement ME Design simulations. The predicted rutting and fatigue cracking performance of the five field sections were then employed to determine the pavement condition of the sections.

The results of the Pavement ME design simulations were used in conjunction with the RIDOT Pavement Structural Health Index (PSHI) to determine the change in condition of each of the pavement sections. The Pavement Structural Health Index is a tool used to assess and monitor the condition of flexible pavements. It is a weighted average that is determined from a comprehensive scoring system which, accounts for distresses such as: International Roughness Index (IRI), rutting, cracking (i.e. longitudinal, transverse, alligator, and block), and patch failure. The weight distribution of the pavement distresses accounted for in the 
RIDOT PSHI scoring system are presented in Table 2. The scoring system for each pavement distress typically ranges from 0 to 100 and the score depends on value of the measured distress. For instance, the distress score for IRI, rutting and cracking is reliant on whether the measured roughness, cracking and rutting falls within a particular range of values. The change in PSHI over time was subsequently used to determine the total life cycle cost of each pavement section.

Table 1. Pavement ME Design Inputs.

\begin{tabular}{llll}
\hline Vehicle Class & Distribution $(\%)$ & Other Inputs & \\
\hline Class 4 & 06.62 & AADT & 5800 \\
Class 5 & 68.59 & AADTT & 240 \\
Class 6 & 09.37 & Traffic Growth Rate (\%) & 1.3 \\
Class 7 & 01.64 & HMA Thickness (mm) & 114.3 \\
Class 8 & 03.41 & Base Thickness $(\mathrm{mm})$ & 203.2 \\
Class 9 & 10.10 & Subbase Thickness $(\mathrm{mm})$ & 203.2 \\
Class 10 & 00.23 & Surface Course HMA Binder Grade & PG 64-28 \\
Class 11 & 00.00 & Intermediate Course HMA Binder Grade & PG 64-22 \\
Class 12 & 00.00 & Base Modulus (kPa) & Varies \\
Class 13 & 00.04 & Subbase Modulus (kPa) & Varies $^{*}$ \\
\hline
\end{tabular}

Table 2. RIDOT Pavement Structural Health Index Scoring System Weight Distribution.

\begin{tabular}{ll}
\hline Pavement Distress & $\begin{array}{l}\text { Weight Distribution of Distress Scores } \\
\text { in RIDOT PSHI Scoring System }\end{array}$ \\
\hline Alligator Cracking & 16 \\
Longitudinal Cracking & 7 \\
Transverse Cracking & 7 \\
Block Cracking & 10 \\
Patch Failure & 20 \\
Total Rutting & 10 \\
International Roughness Index (IRI) & 30 \\
\hline
\end{tabular}

\section{RESULTS AND DISCUSSION}

\subsection{Back-calculated moduli values}

The back-calculated moduli values for all pavement sections considered in this study is shown in Figure 2. Based on the results presented in this figure, the HMA layers in all sections had the highest moduli values. This trend was expected because HMA layers are usually constructed using better-controlled and better-performing materials when compared to other layers. All other layers (i.e., base, subbase, and subgrade) had relatively the same backcalculated moduli values (i.e., approximately $241 \mathrm{MPa}$ ) with the exception of the cement stabilized bases layer in Section 3 . 


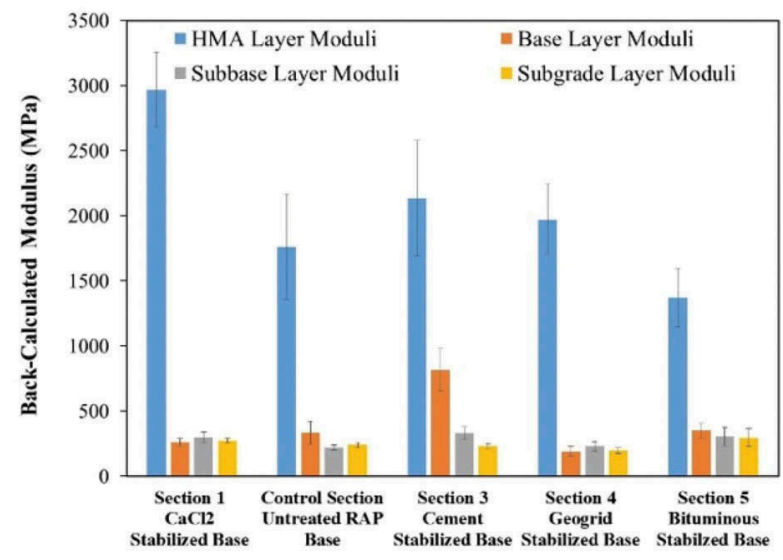

Figure 2. Back-calculated layer moduli of all five pavement sections.

\subsection{Predicted pavement performance}

The results of the Pavement ME Design simulations are shown in Figure 3. The total predicted fatigue cracking in the control section as well as sections $1\left(\mathrm{CaCl}_{2}\right)$ and 5 (bituminous stabilized base) were relatively similar (i.e., approximately $312.5 \mathrm{~m} / \mathrm{km}$ ). These results indicate that the control section as well as sections 1 and 5 have relatively the same susceptibility to fatigue cracking. Section 3, which contained the cement treated base layer, had lower total predicted fatigue cracking value than the control section. This observation implied that the cement treated improved the fatigue life of flexible pavements. The results in Figure 3a also show that section 4 (geogrid stabilized base) may be more prone to fatigue cracking than the control section. This is because the total predicted fatigue cracking for section 4 was approximately $56 \%$ higher than that obtained for the control section.

The results of the total predicted rutting for all sections is presented in Figure $3 \mathrm{~b}$. The total predicted rutting for the control section as well as sections 1 and 5 were similar. This indicated that the rutting susceptibility of these pavement sections was similar. The results in Figure $4 \mathrm{~b}$ also show that the total predicted rutting for section 4 (geogrid stabilized base) was $23 \%$ higher than that obtained for the control section. This suggested that using geogrids to stabilize aggregate base layers may have a negative impact on flexible pavements' rutting life.

The results of the predicted IRI on all the pavement sections considered in this study is illustrated in Figure 3c. Section 4 (geogrid stabilized base) had the highest IRI after the 20 year analysis period (i.e., $2.23 \mathrm{~m} / \mathrm{km})$ followed by sections $1\left(\mathrm{CaCl}_{2}\right.$ stabilized base), 2 (untreated base), and 5 (bituminous stabilized base) which had an IRI of $2.17 \mathrm{~m} / \mathrm{km}$. Section 3 (cement stabilized base) had the lowest IRI of all sections after the 20 year analysis period (i.e., $2.15 \mathrm{~m} /$ $\mathrm{km})$. Generally, the IRI of sections that contained the $\mathrm{CaCl}_{2}$, bituminous, and cement stabilized bases had almost identical predicted IRI values as the section that contained the untreated base. However, section 4 (geogrid stabilized base) consistently had higher predicted IRI values than the control section throughout the 20 year analysis period. These results suggests that pavement ride quality deteriorated at a faster rate on section 4 when compared to all other sections. 


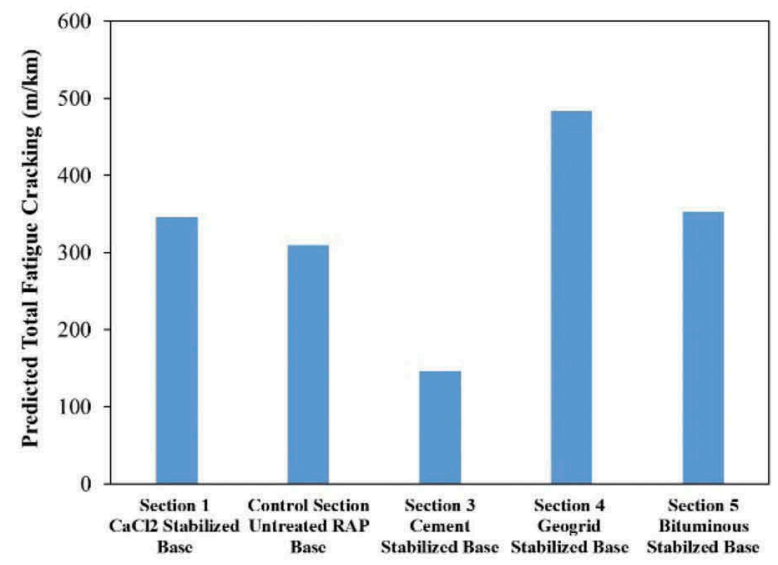

(a)

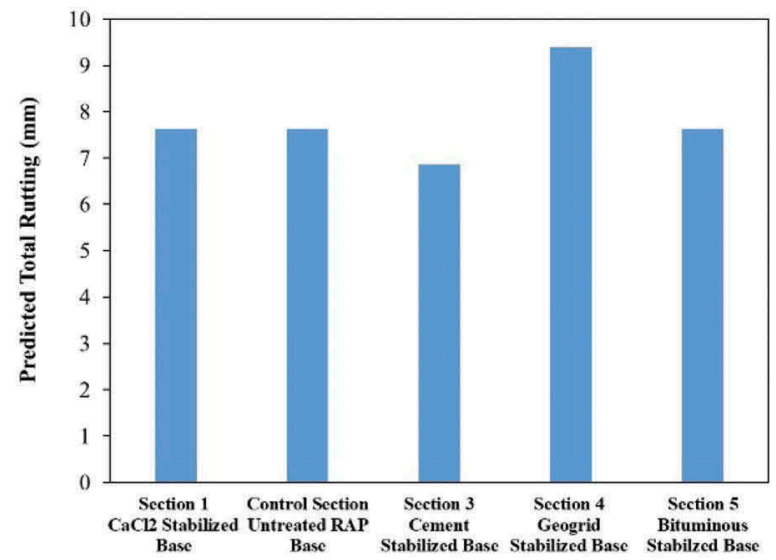

(b)

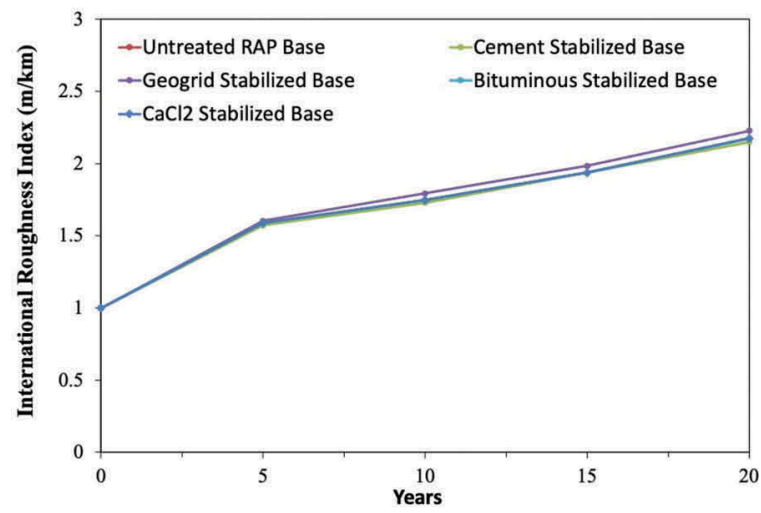

(c)

Figure 3. Pavement ME Design simulation results: (a) predicted fatigue cracking (b) predicted rutting and (c) predicted International Roughness Index. 


\subsection{Comparison of pavement condition}

The PSHI of the five pavement sections evaluated in this study was used to qualitatively classify the pavement condition and compare the life cycle costs of the sections. The pavement condition was defined as excellent, good, fair, poor, or failed based on the PSHI score. PSHI scores typically range from 0 to 100 . However, the range of the PSHI scores in this study ranged between 0 and 70 because the scope of the study did not account for block cracking and patch failure. The final PSHI scores were therefore calculated as percentages; with 70 being the total or maximum PSHI score. Pavement condition was classified as excellent when the PSHI scores of the pavement section fell within the 90.5 to $100 \%$ range. Pavement condition was classified as good, fair, poor, and failed when the PSHI score fell within 84.1 to 90.5 $\%, 75.6$ to $84.1 \%, 64.5$ to $75.6 \%$, and 0 to $64.5 \%$, respectively.

Figure 4 presents the change in PSHI of each pavement section during the 20 year Pavement ME analysis period. The cement stabilized base section underwent the smallest reduction in PSHI (i.e., 100 to 78.4) where pavement condition transitioned from excellent to fair. The geogrid stabilized base section experienced the largest reduction in PSHI (i.e., 100 to 72.4) which reflected a change in pavement condition from excellent to poor. The sections that contained the untreated RAP, $\mathrm{CaCl}_{2}$ stabilized, and bituminous stabilized bases had a relatively similar overall reduction in PSHI throughout the analysis period. These results suggested that the cement stabilized base generally improved the overall performance of the flexible pavement section while the $\mathrm{CaCl}_{2}$ and bituminous stabilization had little to no effect on the overall performance of the flexible pavement section. The results also implied that addition of the geogrid reinforcement negatively impacted on the overall performance of the flexible pavement section.

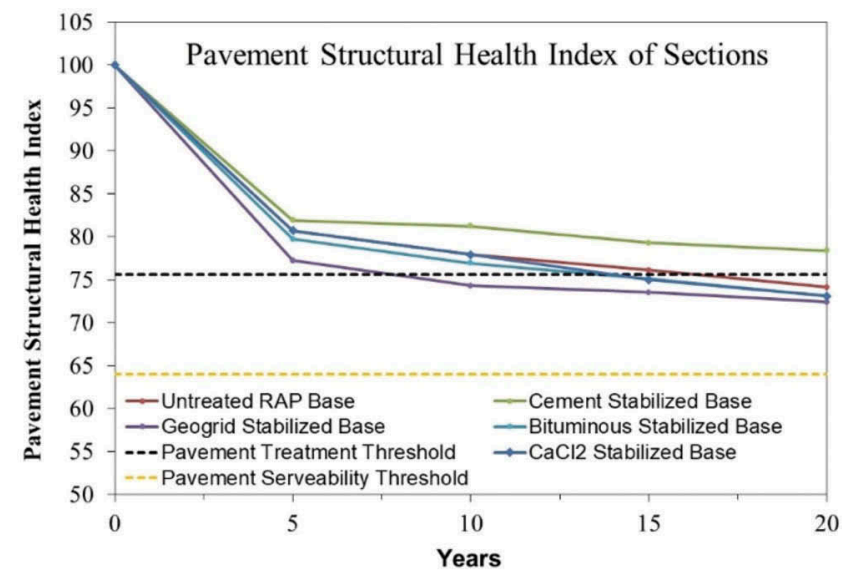

Figure 4. Change in pavement structural health index of pavement sections.

\subsection{Comparison of pavement section life cycle costs}

A life cycle cost analysis was performed to gain insight about the cost effectiveness of performing FDR of the flexible pavements sections using the stabilizing agents considered in this study. The cost of initial construction and rehabilitation were the only costs considered in the cost analysis. No discounting interest rate was factored in the life cycle costs calculations to maintain a conservative estimate regarding future rehabilitations. The pavement rehabilitation costs was determined using the time required for the PSHI of the pavement sections to reach 
the pavement treatment threshold during the analysis period. This is because preservation treatments are typically applied to the surface layers of flexible pavements when this occurs. A two-inch mill and overlay was selected as the treatment of choice when the condition of the pavement sections became "poor" because it adds more years of pavement serviceability (5 years) when compared to other treatments used in RI. The total pavement rehabilitation cost for the sections was determined by multiplying the amount of treatment applications required during the 20 year Pavement ME analysis period by the cost of conducting a mill and overlay (\$142,000 per lane mile).

The total life cycle cost of each pavement section is presented in Table 3 . The total life cycle cost of the pavement sections was determined by adding the initial pavement construction costs to their respective rehabilitation costs over the 20 year analysis period. Based on the results, the geogrid stabilized base section had the highest total life cycle cost of all sections. This is because the pavement section required three mill and overlay interventions in the $8^{\text {th }}$, $13^{\text {th }}$, and $18^{\text {th }}$ years of the analysis period. The untreated base section had the lowest total life cycle cost because it had the lowest initial construction costs of all sections and only required one mill and overlay application in the $15^{\text {th }}$ year of the analysis period. The bituminous, $\mathrm{CaCl}_{2}$ and cement stabilized base sections had a relatively similar total life cycle cost which, was slightly higher than that of the control section. This is because the bituminous and $\mathrm{CaCl}_{2}$ stabilized base sections had similar initial construction costs and required two mill and overlay interventions during the analysis period. On the other hand, the cement stabilized base section required no rehabilitation during the analysis period. However, the comparatively higher initial construction cost offset the total life cycle cost of that pavement section. These results suggested that geogrid, $\mathrm{CaCl}_{2}$ bituminous and cement stabilization was not cost effective. This is because the geogrid, $\mathrm{CaCl}_{2}$ and bituminous stabilized base section performed worse than the control section at a slightly higher life cycle cost. In addition, it is noted that the cement stabilized base section provided more years of serviceability than the control section However, the high initial cost of cement stabilization makes it less cost effective than the control section.

Table 3. Total life Cycle cost of Pavement Sections.

\begin{tabular}{lll}
\hline Pavement Section & $\begin{array}{l}\text { Initial Construction Cost } \\
\text { (\$ in millions) per lane mile }\end{array}$ & $\begin{array}{l}\text { Total Life Cycle Cost } \\
\text { (\$ in millions) per lane mile }\end{array}$ \\
\hline Untreated RAP Base & 3.69 & 3.84 \\
Bituminous Stabilized Base & 3.78 & 4.06 \\
$\mathrm{CaCl}_{2}$ Stabilized Base & 3.80 & 4.08 \\
Cement Stabilized Base $_{\text {Geogrid Stabilized Base }}$ & 4.02 & 4.02 \\
\hline
\end{tabular}

\subsection{Conclusions}

This study was initiated with the aim of determining the cost effectiveness of utilizing various types of stabilizers in the base layer of flexible pavements. Based on the results of this study it was determined that:

- The section that contained the geogrid stabilized base had the highest predicted fatigue cracking and rutting of all sections while the predicted rutting and cracking on the cement stabilized base section was lowest.

- Geogrid, $\mathrm{CaCl}_{2}$, or bituminous stabilization of the base layer did not significantly increase the overall stiffness of that layer. In fact, full depth reclamation with these stabilizing 
agents caused the pavement sections to have less years of serviceability than the control section, at a higher life cycle cost.

- Cement stabilization of the base layer during full depth reclamation is also not a cost effective option during full depth reclamation. This is because the high initial construction cost of cement stabilization makes it less cost effective than untreated bases even though it provides more years of serviceability.

\section{REFERENCES}

Abu-Farsakh, M., Souci, G., Voyiadjis, G. and Chen, Q. 2012. Evaluation of Factors Affecting the Performance of Geogrid Reinforced Granular Base Material Using Repeated Load Triaxial Tests. Journal of Materials in Civil Engineering, Vol 2, No. 2, pp.72-83.

Hungener, M., Partl, M. and Morant M., 2014. Cold Asphalt Recycling with 100\% Reclaimed Asphalt Pavement and Vegetable Oil-based Rejuvenators. Road Material and Pavement Design, Vol.15, No. 2, pp. 239-258.

Ogundipe, O. 2014. Strength and Compaction Characteristics of Bitumen-Stabilized Granular Soil. International Journal of Scientific \& Technology Research. Vol. 3, No. 9,

Tang, X., Chehab, G. and Palomino, A. 2008. Evaluation of Geogrids for Stabilizing Weak Pavement Subgrade. International Journal of Pavement Engineering. Vol. 9, No 6, pp. 413-429.

Tao, M., Wang, H., Zhao, Y. and Huang, X. 2015. Laboratory Investigation on Residual Strength of Reclaimed Asphalt Mixture for Cold Recycling. International Journal of Pavement Research and Technology. Vol. 8, No. 1.

Wang, Y., Ma, X. and Sun, Z. 2010. Shrinkage Performance of Cement-Treated Macadam Base Materials. Proceedings of Traffic and Transportation Studies, pp. 1378-1386. 